\title{
O uso Metodologias Ativas para Ensino de IHC
}

\author{
Julio Guido \\ Militão \\ UNIFOR \\ Fortaleza, Brasil \\ militao@unifor.br \\ Marilia Mendes \\ UFC \\ Russas, Brasil \\ marilia.mendes@ufc.br
}

\author{
Elizabeth \\ Furtado \\ UNIFOR \\ Fortaleza, Brasil \\ elizabet@unifor.br
}

\author{
Patrícia Vasconcelos \\ ESTÁCIO-FIC \\ Fortaleza, Brasil \\ patricia.campos@estacio.br
}

\author{
Rafaela Lisboa \\ UNIFOR \\ Fortaleza, Brasil \\ rafaela@unifor.br
}

\begin{abstract}
APRESENTAÇÃO
A área de IHC tem apresentado uma importância cada vez maior nos cursos de graduação em Computação. Durante o Simpósio Brasileiro de Fatores Humanos em Sistemas Computacionais, em novembro de $2006 \mathrm{em} \mathrm{Natal/RN} \mathrm{(IHC}$ 2006), foi realizado o primeiro grupo de trabalho (GT) sobre currículos de IHC [7]. A recomendação de programa para uma disciplina da área envolvia: (i) introdução à Interação Humano-Computador, (ii) fundamentos teóricos, (iii) avaliação de IHC, (iv) projeto de interação com o usuário e (v) processo de design em IHC [7].
\end{abstract}

O planejamento didático-pedagógico de uma disciplina de IHC requer o emprego de metodologias de ensino que auxiliem os discentes a desenvolver todas as competências associadas aos seus objetivos. Para tanto, o uso de Metodologias Ativas (MA) [2], por sua vez, deve promover a inserção do aluno no processo de ensino e aprendizagem. Assim, o estudante deixa de ser um agente passivo (que apenas escuta) e passa a ser um membro ativo na construção do saber por meio de estímulos sobre o conhecimento e análise de problemas. $\mathrm{O}$ aprendente é convidado a participar com suas opiniões e ideias para promover transformações na sociedade. O professor deixa de ser o ator principal em sala de aula e se torna um mediador do conhecimento.

De acordo com Diesel, Baldez e Martins [2], os principais princípios das MA são: aluno como centro do ensino e de aprendizagem, autonomia, reflexão, problematização da realidade, trabalho em equipe, inovação e o professor como mediador, facilitador e ativador.

As experiências unindo MA e IHC foram realizadas na Universidade Federal do Ceará - UFC, na Universidade de Fortaleza - UNIFOR e no Centro Universitário Estácio do Ceará

Permission to make digital or hard copies of all or part of this work for personal or classroom use is granted without fee provided that copies are not made or distributed for profit or commercial advantage and that copies bear this notice and the full citation on the first page. Copyrights for components of this work owned by others than the author(s) must be honored. Abstracting with credit is permitted. To copy otherwise, or republish, to post on servers or to redistribute to lists, requires prior specific permission and/or a fee. Copyright 2018 SBC.

IHC 2018, Anais Estendidos do XVII Simpósio Brasileiro sobre Fatores Humanos em Sistemas Computacionais

Outubro 22-26, 2018, Belém, Brasil

Minicursos pelos autores nas disciplinas de graduação dos cursos de Ciência da Computação. Pretende-se apresentar durante o Mini-Curso as MA utilizadas para abordar os seguintes conceitos: Interface x Interação; heurísticas de Nielsen; Prototipação de baixa fidelidade; Recomendações ergonômicas (padrões) e Modelagem do usuário pelo uso de Personas (ver Tabela 1).

\section{SUMÁRIO ESTENDIDO}

$\mathrm{O}$ mini-curso "O uso Metodologias Ativas para ensino de IHC" pretende apresentar um conjunto de práticas e MA aplicadas a conteúdos de Interação Humano-Computador em um curso em nível de graduação. Nas MA [3] o aluno é o protagonista do seu processo de construção do saber, pois ele terá uma maior responsabilidade para alcançar seus objetivos educacionais.

\section{Tópico 1. Embasamento Teórico}

Apresentação sucinta dos objetivos e vantagens da MA. Essa metodologia de ensino propicia maior interação em sala de aula e exige comprometimento da turma para que todos possam se desenvolver. Como resultado, os alunos ficam mais motivados para frequentar a universidade e mais interessados em aprender. Ou seja, "priorizam o envolvimento maior do aluno, com MA como o ensino por projetos de forma mais interdisciplinar, o ensino híbrido ou blended e a sala de aula invertida" [3]. (Tempo: 30 minutos).

\section{Tópico 2. Apresentação das Práticas utilizadas usando Metodologias Ativas}

Diante desta perspectiva teórica apresentada no Tópico 1 , o mini-curso apresenta o passo a passo de experiências realizadas a partir do emprego de MA em disciplinas de IHC (Tabela 1) e os resultados obtidos pela sua aplicação no contexto de sala de aula de graduação em três universidades (UFC, UNIFOR, ESTÁCIO). Cada uma das MA elencadas na Tabela 1 aplicaremos uma atividade que levará aproximadamente 25 minutos.

Tópico 3. Propostas avaliativas das práticas realizadas A avaliação não deve ser apenas quantitativa, mas eminentemente qualitativa. Propõe-se no minicurso um conjunto de ações para avaliação cognitiva, procedimental e atitudinal. As ações são baseadas, por exemplo, em feedback imediato 
via Quiz e provas Online e pela realização cruzada de atividades entre equipes e turmas. [2]

Tópico 4. Visão de Futuro para outros Conteúdos

Nesse tópico propõe-se uma troca de conhecimentos para montar um rol de práticas que podem ser utilizadas nos demais conteúdos. A proposta é gerar um documento que possa servir de guia para os docentes da área.

\begin{tabular}{|c|c|c|}
\hline Conceito & Prática & $\begin{array}{c}\text { Metodologia } \\
\text { Ativa }\end{array}$ \\
\hline $\begin{array}{l}\text { Interface x } \\
\text { Interação }\end{array}$ & $\begin{array}{c}\text { Utilização de Realidade aumen- } \\
\text { tada para apresentar os concei- } \\
\text { tos. }\end{array}$ & $\begin{array}{c}\text { Realidade } \\
\text { Aumentada [5] }\end{array}$ \\
\hline $\begin{array}{l}\text { Heurísticas } \\
\text { de } \\
\text { Nielsen }\end{array}$ & $\begin{array}{l}\text { Identificação dos princípios em } \\
\text { sistemas aplicando questioná- } \\
\text { rios individuais e em equipe. }\end{array}$ & $\begin{array}{l}\text { Team Based } \\
\text { Learning }[1]\end{array}$ \\
\hline $\begin{array}{l}\text { Prototipação } \\
\text { de baixa fi- } \\
\text { delidade }\end{array}$ & $\begin{array}{l}\text { Desenvolvimento de um protó- } \\
\text { tipo de Copo Inteligente }\end{array}$ & Simulação [2] \\
\hline $\begin{array}{l}\text { Recomenda- } \\
\text { ções ergonô- } \\
\text { micas }\end{array}$ & $\begin{array}{l}\text { Identificação e aplicação dos } \\
\text { padrões em softwares usando } \\
\text { imagens (Jogos dos } 7 \text { erros) }\end{array}$ & $\begin{array}{l}\text { Grupos Opera- } \\
\text { tivos com Ga- } \\
\text { mificação [4] }\end{array}$ \\
\hline $\begin{array}{l}\text { Modelagem } \\
\text { do usuário }\end{array}$ & $\begin{array}{l}\text { Definição de um Cenário con- } \\
\text { creto para modelar usuários }\end{array}$ & $\begin{array}{l}\text { Aprendizagem } \\
\text { Baseada em } \\
\text { Problemas [6] }\end{array}$ \\
\hline
\end{tabular}

Tabela 1. Conteúdos x Práticas x Metodologias

PÚBLICO-ALVO

Pesquisadores, Professores e demais interessados na área. Ideal: conhecimentos prévios da teoria de IHC.

\section{BIOGRAFIA DOS AUTORES}

Julio Guido Oliveira Militão é Graduado em Ciência da Computação pela Universidade Estadual do Ceará - UECE e mestrado pela Pontifícia Universidade do Rio de Janeiro PUC-Rio. Diretor técnico da MIL Tecnologia e professor da Universidade de Fortaleza- UNIFOR.

Marília Soares Mendes é Professora e Coordenadora de Curso de Ciência da Computação no Campus da UFC em Russas. Doutora em Ciência da Computação pela Universidade Federal do Ceará (UFC). Mestre em Informática Aplicada e Bacharel em Ciência da Computação pela Universidade de Fortaleza (UNIFOR).

Maria Elizabeth Sucupira Furtado é Pesquisadora em IHC (Interação Humano-Computador). Possui graduação em tecnologia de processamento de dados pela UFC, mestrado em Ciência da Computação pela UFCG e doutorado em Informatique - Universite dAix-Marseille III (Droit, Econ. et Sciences- França).

Patrícia Freitas Campos de Vasconcelos é Professora do curso de Sistemas de Informação e Coordenadora Acadêmica do Centro Universitário Estácio do Ceará
(ESTÁCIO-FIC). Doutora em Informática Aplicada, Mestre em Informática Aplicada e Bacharel em Informática pela UNIFOR e Especialista em Tecnologias da Informação pela Universidade Federal do Ceará (UFC).

Rafaela Ponte Lisboa é Docente e Assessora Pedagógica do Centro de Ciências Tecnológicas da UNIFOR. Doutora e Mestre em Educação Brasileira pela Universidade Federal do Ceará. Tem graduação em Comunicação Social - Jornalismo pela Faculdade Integrada do Ceará e em Pedagogia pela Universidade Federal do Ceará.

\section{DURAÇÃO DO MINICURSO}

Três horas

\section{IDIOMA EM QUE SERÁ MINISTRADO}

Português

INFRAESTRUTURA E MATERIAIS NECESSÁRIOS E DESEJÁVEIS

Data-show e Notebook com Câmera.

\section{REFERÊNCIAS BIBLIOGRÁFICAS}

1. BOLLELA, V. R. Aprendizagem baseada em equipes: da teoria à prática. Disponível em:

$<$ https://edisciplinas.usp.br/pluginfile.php/2898402/m od resource/content/3/TEAM-

BASED\%20LEARNING.pdf $>$. Acesso: 16 jun 2018.

2. DIESEL, Aline; BALDEZ, Alda Leila Santos; MARTINS, Silvana Neumann. Os princípios das metodologias ativas de ensino: uma abordagem teórica. Revista Thema, v. 14, n. 1, p. 268-288, 2017.

3. MORÁN, José. Mudando a educação com metodologias ativas. 2015. Disponível em:

$<$ http://www2.eca.usp.br/moran/wp-content/uploads/2013/12/mudando_moran.pdf $>$. Acesso: $20 \mathrm{mar}$ 2018.

4. MATTAR, João. Games em educação: como os nativos digitais aprendem.Disponível em:

$<$ http://www.ucs.br/etc/revistas/index.php/conjectura/ article/download/334/288> Acesso:16 jun 2018.

5. NIELSEN, B. L, BRANDT, H., SWENSEN, H. Augmented Reality in science education - affordances for student learning. Nordina, 2012 Disponível em: $<$ https://www.journals.uio.no/index.php/nordina/articl e/download/2399/3336>. Acesso:16 jun 2018.

6. Problem-based learning (PBL). Disponível em: https://www.cte.cornell.edu/teaching-ideas/engagingstudents/problem-based-learning.html. Acesso: $23 \mathrm{abr}$ 2018.

7. SILVEIRA, Milene. PRATES, Raquel. Uma Proposta da Comunidade para o Ensino de IHC no Brasil .

Anais do XXVII SBC. Disponível: http://www.lbd.dcc.ufmg.br/colecoes/wei/2007/008.pdf. Acesso em: 23 abr de 2018. 